Reiss.-Zeitschr. f. Augenheilk., Vol. XIX, p. 505, 1908.

Mohr.-Zeitschr. f. Augenheilk., Vol. XX, p. 270, 1908.

Lauber.-Zeitschr.f. Augenheilk., Vol. XX, pp. 388, 583, 1908.

Herczogh.-Zeitschr. f. Augenheilk., Vol. XX, p. 270, 1908.

Fraenkel.-Ann. d'Ocul., Vol. CXLI, p. 101, 1909.

Stephenson. -The Ophthalmoscope, Vol. VII, p. 78, 1909.

Carr.-The Ophthalmoscope, Vol. VII, p. 742, 1909.

Coats. - . The pathology of colomboma at the nerve entrance." Roy. Lond. Ophthal. Hosp. Reps., Vol. XVII, p. 215.

Williams. -Ann. of Ophthal., Vol. XXII, p. 638, 1913.

Henderson, E. E-Proc. Roy. Soc. Med., Section of Ophthalmology, Vol. VII, p. 144

\title{
ON BITEMPORAL CONTRACTION OF THE VISUAL FIELD IN PREGNANCY
}

IT is generally known that pregnancy may be the cause of many diseases of the eye. Among the morbid changes, which occur in the course of regular pregnancy, may be cited: ecchymosis of the lids and of the conjunctiva, accommodative and muscular asthenopia, hyperaesthesia of the retina and night-blindness. Besides these slight and fleeting disturbances, there occur in pregnancy serious diseases, such as inflammation of the cornea and the uveal tract, diseases of the retina and optic nerve.

The above-mentioned diseases which depend in the main upon conditions associated with pregnancy, namely upon disorders of nutrition and disturbances of the internal secretion, are rare complications of pregnancy. According to Winckel their percentage is 1.4 per cent., according to Bastide only 1.3 per cent. This category contains only those diseases which are closely associated with pregnancy, usually recurring in subsequent pregnancies and disappearing after delivery or abortion.

Up to the present time no constant changes in the visual apparatus in connection with normal pregnancy, such as those found in the hypophysis, suprarenal and thyroid glands, were obtained.

Bosse (1900) tried to show that 75 per cent. of all women in a normal pregnancy show some disorders of the optic nerve, such as congestion and oedema of the disc, but the observations of Bosse were not confirmed by the investigations of other authors, such as Sandmann (1901), Polte (1905), and Majewski (1910). 


\section{II.-Historical sketch concerning the bitemporal contraction of the visual field in pregnancy}

In hị research on visual fields in pregnancy Finlay (1922), as the result of 31 observations concluded, that "during pregnancy there often occurs as a result of the normal hypertrophy of the pituitary gland in connection with this state, a compression of the chiasma which manifests itself by changes in the visual fields in the nature of a bitemporal contraction."

Finlay's work, read at a meeting of the International Congress of Ophthalmology, Washington, April, 1922, awoke much interest among those present. In the discussion Maud Carvill stated that she also had examined the visual fields of $6 \pi$ gravid women and found that 89 per cent. showed bitemporal contraction of greater or less extent. The contractions were more marked in multiparae.

For the sake of historical exactness 1 must add that bitemporal contractions of visual fields in pregnancy had often been observed before Finlay. Thompson (1901) noticed a case of bitemporal hemianopsia with optic neuritis in a young gravid person. Similar cases were published by Reuss and Nolen (1908); Bellinzona and Tridontani (1904) noted in 24 gravid women, with normal acuity of vision, changes in the visual fields in the nature of a bitemporal contraction, which increased as the pregnancy progressed and were more obvious in primiparae. The colourfields were concentrically contracted. Postpartum all changes disappeared. Forti (1910) also noted in pregnancy a contraction of the field for white, and that the nasal part was less contracted than the temporal. These alterations appeared chiefly in primiparae but did not progress in the later period of pregnancy. The limits of the colour-fields showed some interlacing.

Bellinzona, Tridontani and Forti explained the disorders of the visual fields by vasomotor disturbances, similar to those occurring in hysteria.

Nevertheless the views of authors, concerning the existence of any contraction of the visual field in a regular pregnancy, were not all at that time, compatible, because Polte (1905) found quite different results, when in 12 cases of normal pregnancy he observed no trace of changes in the visual field. Berger and Loewy (1906) also rejected the possibility of the existence of such changes.

More careful studies on the question of hemianopsia in normal pregnancy date from Igersheimer (1916), after Finlay and Carvill published their works, explaining the changes described by the mechanical pressure brought to bear on the chiasma by the enlarged pituitary gland. This based the pathogenesis of hemianopsia during normal pregnancy on quite different foundations to those of previous authors. It is true that Nolen (1908), citing a case of his own, advised in certain diseases of the eye, 
accompanied by alterations in the visual field in pregnancy, to take into consideration the lesion of the chiasma produced by the hypertrophic pituitary body. Reuss interpreted also in the same way the appearance of temporal hemianopsia in one of his patients in the course of the fourteenth, fifteenth, and sixteenth pregnancy; but these observations concerned only single and rare cases.

Finlay's investigations were repeated by Löhlein (1923) who confirmed in a series of 54 cases, in 78 per cent. the temporal contraction of visual fields in the last month of pregnancy. This contraction usually increases until the day of delivery and disappears on the tenth day after it. Defect for colours, especially for red and green, precedes that for white. The alterations appear more frequently in multiparae and in them the return to the normal state takes more time.

According to Löhlein the examination of the visual fields before delivery may give an idea of the degree of the hypertrophy of the pituitary gland. If it could be proved that there exists a depedency between the extension of the field contractions and the force of the labour pains, examination of the visual fields before delivery might indicate, so Löhlein thinks, whether the patient may expect normal, feeble, or strong pains.

Prompted by Professor Szymanski I have examined in the Obstetrical Clinic of the University and the Obstetrical Department of the District Military Hospital in Vilno, a series of visual fields in pregnant women.

While I was engaged in this research observations were published by Schöninger, Holm, Stargardt and Schall, Beckerhaus, Metzger, and Richter contradicting the results of previous authors. The work of Schöninger was founded upon 24 cases of normal pregnancy, that of Holm upon 45, Stargardt and Schall upon 58, Beckerhaus 150, Metzger 56, and that of Richter's upon 81 cases. All these investigators found in only three cases slight bitemporal contractions of the visual fields. Meantime de Schweinitz (1923) and Lloyd Mills (1924) confirmed the existence of the changes in the visual fields as described by Finlay and Carvill. Ashikaga (1924) agrees with the opinions of Finlay and Löhlein, basing his belief on 20 cases. He adds, however, that his measurements demonstrate more contracted limits of the visual fields in primiparae.

\section{III.-Technique}

One of the main causes of this striking contradiction in the views of the investigators is the diversity and inaccuracy of the investigation of the periphery of the retina in general. Although the question of uniformity of the perimetry is of great importance nevertheless definite results have not yet been obtained. Taking into consideration the imperfection of perimetry, I started, when 
elaborating the technique of my inquiries from the foundation that the measurements should be, as far as possible, in uniform conditions of illumination, contrast, visual angle, and other factors having preponderating influence on the size of the visual field.

In my investigations I made use of Förster's perimeter, for as it is known (Brudzewski, Comberg, Peter, de Schweinitz) this instrument is the most satisfactory for investigating the functions of the peripheral parts of the retina, and therefore to record the contraction of the outer limits of the visual field, which is the subject of my investigation.

The perimeter in use had a radius of $300 \mathrm{~mm} ., 180^{\circ}$ in extent; the breadth of the dead-black arch was $\tau .5 \mathrm{~cm}$., the diameter of the fixation carrier $1 \mathrm{~cm}$., the diameter of the test-object for white (as a rule) $5 \mathrm{~mm}$., then the visual angle $5 / 300$; the colour tests were $10 \mathrm{~mm}$. in diameter; all tests were circular and they were moved by hand. Test-objects of various sizes $(3 \mathrm{~mm} ., 5 \mathrm{~mm} ., 10 \mathrm{~mm}$.) were also used. I did not make use of the self-registering instrument on account of its defects : (1) the motion of the sliding object is usually accompanied by a murmur; (2) the patient first sees the projecting edges of the carrier; (3) the black colour of the carrier wears off after long use, and consequently confusing reflections appear.

The manual moving of the test-object has also this advantage, that by turning the long handle quickly (while the test is attached on one side of the dark cartoon disc attached to the handle) we have the possibility of determining whether the patient really sees the test-object without having his attention turned to it.

In order to detect the early symptoms of lesion of the chiasma, that is the slight contraction outward and upward, Walker, Cushing and Hill recommend the use of a very small testobject of $0.3 \mathrm{~mm}$. in diameter. Hess and Kölner, however, consider that, when using such a small test in the examination of the peripheral limits of the visual field, pseudo-contractions appear, which can with difficulty be distinguished from real ones. The local adaptation of the retina (Lokaladaption) and the formation of false scotomata and contractions depend upon the facts that very small tests become invisible in the peripheral parts of the visual field, unless moved with great speed.

The movement of the white test (the coloured test will be described later) was carried out at medium rate from without inward. It is known that too slow a movement of the test fatigues the eye and causes the local adaptation, while too fast a movement renders the eye insensible to the test-object. The movement of the test-object was a steady and even one.

In discussing the rapidity of movement of the test I cannot pass over in silence the work of Kestenbaum (1924), concerning 
peripheral perimetry. Kestenbaum stated that the eye perceived in the most peripheral circumference of the visual field only the motion of the test-object, but not its white colour. If the test being in the limits of "sensation of motion" is not moved, it will become imperceptible, when it is in the limits of white sensation then, even in the absence of movement, it is perceived. In normal cases the difference between the respective boundaries when using the middle-sized tests, possesses no clinical meaning, on the contrary, in pathological cases there appears a rather considerable dissociation between these limits. In several cases of normal pregnancy I observed the visual field in the above-mentioned way and consequently the difference between the limits of "sensation of motion" and "sensation of white," reached from $5^{\circ}$ to $10^{\circ}$. In testing the field for colour saturated colours were used. The movement of the test was performed centrifugally, quickly and steadily, because according to Hess, unequal and too slow a motion of the coloured test would cause the above-mentioned local adaptation. The patient did not know beforehand what colour was coming. The results were only noted when the patient perceived the right colour. I made my observations with red and green and in diffused daylight. Only persons with normal coloursense were examined.

Engelking's colour test-objects as previously used were found to contain impure colours, so that with them the boundaries for the red and green are much contracted. The recognition of saturated colours is easier, and particularly that of the gradual transformation of a saturated colour.

The measurements of the visual field were made in diffuse daylight in a room having a large window which looked to the north. Many a time I have been obliged to make my observations at night by an electric lamp ( 100 volt), placed behind the head of the patient in such a manner that the arm of the perimeter might be equally illuminated in all meridians. In all measurements I took care that the line uniting the eye of the patient with the centre of the perimeter should run strictly horizontally, as this has a marked influence on the extension of the vertical meridians of the visual field. I also paid attention to the prevention of lateral movements of the patient's head, as any neglect of this considerably alters the boundaries in the horizontal meridians of the visual field. During the tests I stopped for a few minutes to rest the patients, as the tests being of relatively long duration, would weary them, the more so since women at the termination of pregnancy are easily fatigued.

Before examination of the second eye I made a longer pause so that the eye, which had been occluded, might be adapted to the illumination. 
To avoid fatigue I tested only in eight meridians. Habitually I began my tests in those meridians in which I expected the least changes, passing on to more careful measurement of the most threatened meridians, viz., up-outwards, because it is here that the earliest changes of the visual field, in cases of a compression of the chiasma by the enlarged pituitary gland make their appearance (Cushing, Wilbrand and Saenger).

In noting the results of my observations in recording the limits of the visual field, I made use of the method suggested by Uribe Troncoso, founded on the principle of always considering the subject in front of the observer, his right side facing the left hand of the latter. Among others this method facilitates the marking and the interpretation of the findings.

In order to compare the results of the visual field as observed in pregnancy with physiological limits I made measurements in ten cases of nulliparae.

Contractions of $5^{\circ}$ were considered to be within the physiological, especially with concentric contraction and when examining with colour-tests. All observations were made by myself.

\section{IV.-Results}

I have examined the visual fields of 81 patients in the last month of pregnancy. The tests were frequently taken on the actual day of parturition. In those cases in which I found contractions I made further investigations on the ninth day after delivery. Forty-six of these persons were primiparae : 19 were in their second pregnancy; 10 in their third pregnancy; 2 in their fourth; 3 in their fifth; and one was in her twenty-third pregnancy. These women were of good intelligence and between 19 and 43 years of age.

The results of my investigations are as follows: in two cases (the twenty-third and fifty-eighth) I found a slight temporal contraction for white and in one of these cases (the twenty-third) only on the right side.

The twenty-third case, 2nd pregnancy: (the location of the meridians of the perimeter chart is so arranged that the zero is placed at the nasal extremity of the horizontal meridian in each eye and the degrees are counted on the upper semicircle to $180^{\circ}$ at the temporal extremity) in the meridian $120^{\circ}$ at $55^{\circ}$; in the meridian $150^{\circ}$ at $65^{\circ}$; temporally outward (meridian $180^{\circ}$ ) at $80^{\circ}$. The boundaries for green were found on this side concentrically contracted. The fifty-eighth case, 3rd pregnancy : bilateral contraction of $10^{\circ}$ out-upward for white on both sides. Three times (the fourteenth, fifty-third, and fifty-fourth cases) I found a temporal contraction only for coloured test-objects, namely : the fourteenth case, 3 rd pregnancy, for red outward, $30^{\circ}$; for green 
outward, $10^{\circ}$. The fifty-third case, 1st pregnancy; change in the nature of a temporal contraction (outward, $15^{\circ}$ ) for green on both sides.

The fifty-fourth case, 1st pregnancy : temporal contraction for red and green only on the left side. For red outward, $30^{\circ}$; for green outward, $10^{\circ}$.

In one case (fiftieth) there appeared a concentric contraction for red and green, and in the forty-sixth case there was a relative scotoma for green.

Many authors (Birch-Hirschfeld, Comberg, Ferree and Rand, Foucoult, Gleb and Goldstein, Hess, Kleinsasser, Simon) state that there exists in a great many normal eyes scotomata, particularly in the peripheral areas of the visual field and especially after a certain fatigue of the retina. The change in the forty-sixth case can be reckoned with the so-called "physiological." If I do not count the fiftieth case with concentrical contraction for coloured tests, which I must treat with the greatest circumspection, there will remain as a result of my observations five cases with slight temporal contractions of the visual fields.

The above-cited alterations appeared twice in primiparae (on 46 observed primiparous gravid women); once in the second pregnancy (on 19 women in the second pregnancy) and twice in the third pregnancy (on 10 women).

The visual field returned after delivery to its normal state in five cases (the twenty-third, forty-sixth, fiftieth, fifty-third, fiftyeighth). In two cases further observations could not be made. The above-mentioned contractions, observed in my five cases, might be considered as a sign of fatigue of the eye, or as a stigma hystericum, which occurs, as well as other hysterical disturbances in the last period of pregnancy, for according to Rönne, in hysteria the possibility of finding various forms of the visual field, including even hemianopsia, must be taken into consideration (Hippel, 1925).

Nevertheless, from the observed alterations in the nature of a bitemporal contraction and from the normal hypertrophy of the pituitary gland during pregnancy, the possibility only of a compression, though not in numerous cases, of the chiasma in pregnancy by the enlarged pituitary gland, as manifested by changes in the visual fields must be considered.

As is known, the hypophysis in pregnancy undergoes only in its anterior part any considerable anatomical and functional change. According to Bumm and Seitz the augmented function of the anterior glandular part of the hypophysis is in connection with hypertrophy of the matrix and often occasions in pregnancy acromegalic changes in the face, hands and feet. Various observers long ago surmised that the pituitary was enlarged in pregnancy (Comte, Launios and Mulon, Morandi, Querrini, 
Cagnetto). The above question is treated by Erdheim and Stumme (1909) with great minuteness. As Erdheim and Stumme assert, the average weight of the pituitary gland in nulliparae between 21 and 40 years of age, is $61.8 \mathrm{cg}$. ; its size in transverse measurement (breadth) is $14.4 \mathrm{~mm}$.; in antero-posterior sagittal measurement (thickness) $11.5 \mathrm{~mm}$.; in vertical measurement (height) $5.9 \mathrm{~mm}$. In women in their first pregnancy the figures are as follows: weight $84.7 \mathrm{cg}$., breadth $15.6 \mathrm{~mm}$., thickness $11 \mathrm{~mm}$., height $7.5 \mathrm{~mm}$. The figures in multiparous women are respectively: weight $106 \mathrm{cg}$., size $17.5 ; 11.0 ; 8 \mathrm{~mm}$.

From the fourth month of pregnancy the pituitary gland begins gradually to increase in weight and size, and several weeks after delivery it begins to diminish. The increase of the hypophysis is more marked in multiparae. In comparing these figures it is seen that the overgrowth of the hypophysis takes place only in transverse and vertical measurements (in the last only imperceptibly) while the sagittal diameter remains unchanged on account of the existing obstacles from the bones. As Zander (1897) maintained there exists between the operculum sellae and chiasma a cisterna chiasmatis $1-2.5 \mathrm{~mm}$. in height, so the pituitary must at least increase $5 \mathrm{~mm}$. in height to exert any compression on the chiasma. In several investigations of Erdheim and Stumme such increase took place in multiparous women. As a result of their own investigations Erdheim and Stumme came to the conclusion that during pregnancy the compression of the chiasma cannot be considered as normal. In exceptional cases, such as a high situation of the hypophysis, a flat sella Turcica, or an enlarged cyst of Rathke and considerable increase of the vertical measurement of the hypophysis, a compression of the chiasma may occur in pregnancy.

There has, recently, appeared a work by Parsons Schaeffer (1924) concerning the anatomy of the chiasma, throwing much light on the question of hemianopsia in pituitary tumour and assisting to clear up the problem. From Parsons Schaeffer's investigations it is noted that the visual phenomena in connection with the diseases of the hypophysis are not always an early symptom, and, though bitemporal heminanopsia is the most common visual field defect disturbances of quite another kind appear, sometimes an absolute want of visual changes, above all in the first period of the disease, when the chiasma not being fixed to the base of the skull, yields to compression. According to Parsons Schaeffer, whenever in those cases the chiasma lies behind the dorsum sellae (in 4 per cent.), or when its small part is to be found in front of the dorsum (in the majority of his cases) tumours of the pituitary gland may attain great dimensions and make their way between the optic nerves, and yet may exert no pressure on the chiasma. 
Considering particularly the question of the hypertrophy of the pituitary in pregnancy it would appear from the investigations of Erdheim and Stumme, that compression can only appear in isolated cases. Ashner (1924) agrees with the opinion that the hypophysis rarely attains in pregnancy such a dimension as to produce a compression of the chiasma.

Individuals with a special susceptibility to disturbance of the endocrine glands are particularly liable, in pregnancy, to such disturbances, as, for instance, in the case of Gross (1924) when, after delivery a complete bitemporal hemianopsia accompanied by "distrophia adiposogenitalis" appeared, or that of Frankl (1925), when in the seventh month of pregnancy a transitory amaurosis with acromegaly occurred.

Returning to my own observations I must note that in contradiction to the results of Finlay, Carvill, Löhlein and Ashikaga, I have only found in a few cases of pregnancy temporal contractions of the visual field. Even in the eighty-first case (twenty-third pregnancy) I failed to find any alterations of the visual field. The examination with the Röentgen rays demonstrated no changes in the sella Turcica. The case of twenty-third pregnancy merits attention in this respect, that it concerns a patient in whom four months previously a thyroidectomy had been performed. Experimenters with thyroidectomy, performed on animals, (Stiede, Gley, Biedl, Simpson and Hunter) have observed that as a consequence of these experiments a considerable hypertrophy of the pituitary gland often arises, which might show itself in men by corresponding changes in the visual field, although this did not take place in my case. It is possible that the relatively short time that elapsed from the operation may account for this, though my observation is in accordance with that of Kranz (1925).

I also desire to comment on the question hinted at by Löhlein, as to the possibility of the existence of a proportional relation between the degree of the hypertrophy of the pituitary gland and the strength of the labour pains.

The comparison of the results of $m y$ inquiries on the visual field with the strength of the labour pains appears from my material as follows :

\begin{tabular}{llll|c|c}
\hline & & & $\begin{array}{c}\text { Normal visual } \\
\text { fields. }\end{array}$ & $\begin{array}{c}\text { Temporal } \\
\text { contraction. }\end{array}$ \\
\hline Feeble pains & $\ldots$ & $\ldots$ & 17 & 1 \\
Middle & $\ldots$ & $\ldots$ & $\ldots$ & 23 & 3 \\
Strong & $\ldots$ & $\ldots$ & $\ldots$ & 31 & 1 \\
\hline
\end{tabular}

The examination gave negative results. Holm obtained the aame results. 


\section{V.-Conclusions}

I consider that as a result of my observations I am justified in making the following conclusions.

(1) The manner of clinical investigations of the visual field at present in use, being a subjective method, is therefore affected by numerous physical defects and errors (illumination, colour-tests, the contrast and the size of the object), which must be taken into account in the interpretation of the results.

(2). In few cases of normal pregnancy (6 per cent.) there occurs in the last month of pregnancy a slight temporal contraction of the visual field, which may be occasioned by the hypertrophy of the pituitary body.

(3) On the tenth day after delivery the visual field returns to its normal state.

(4) I did not find any relation between the appearance and extent of the field contractions and the strength of the labour pains.

\section{REFERENCES}

1. Aschner.-- " Biologie und Pathologie des Weibes," von Halban, pp. 635-736.

2. Idem.-Medizinische Klinik, Nr. 48, 1924.

3. Ashikaga. - Nippon Sankakai Zaschi, Nr. 2-3, 1922 ; ref. Klin. Monatsbl. f. Augenheilk., 1924.

4. Bastide. - Thèse de Paris, 1893.

5. Bosse.-Augenhintergründ bei Schwangeren. Arch. f. Augenheilk., p. $167,1900$.

6. Bellinzona and Tridontani.-Ref. v. Hippel.

7. Berger and Loew.y.-- Über Augenerkrankungen sexuellen Ursprungs, p. 90.

8. Beckerhaus. - Zeitschr. f. Augenheilk., p. 180, 1925.

9. Brudzewski.-Clinical perimetry, 1925. (Polish.)

10. Bumm.-Grundriss zum Studium d. Geburtshilfe, 1924,

11. Carvill.-Amer. Jl. of Ophthal., No. 11, p. 885, 1923.

12. Erdmann and Stumme. -Ziegler's Beiträge für Pathol. Anatomie, p. 132, 1909.

13. Finlay.-An Internat. Congress of Ophthai., Washington, p. 144, 1922.

14. Forti.-Klin. Monatsbl.f. Augenheilk., p. 141, 1910.

15. v. Hippel:-Die Krankheiten d. Sehnerven. From Graefe-Saemisch Handb. f. Augenheilk.

16. Idem. -Arch. f. Psychiatrie u. Nervenkr., 1925.

17. Holm.-Acta Ophthal., p. 92, 1924.

18. Igersheimer.-Bericht d. Ophthal. Ges., Heidelberg, 1916.

19. Kestenbaum.-Bericht d. Ophthal. Ges., Heidelberg, p. 37, 1924.

20. Köllner.-Untersuchungsmethoden. From Graefe-Saemisch Handb.f. Augenheilk., 1925.

21. Kranz.-Klin. Monatsbl. f. Augenheilk. p. 456, 1925.

22. Löhlein.-Monatschr. f. Geburtsh. u. Gynäk., p. 129, 1924.

23. Majewski. - Przeglad lekarski (Polish), 1910.

24. Metzger, Simon and Weinberg.-Monatschr. f. Geburtsh. u. Gynäk., p. 140,1925

25. Nolen.-Berl. Klin. Wochenschr., p. 2177, 1908.

26. Polte.-Klin. Monatsbl. f. Augenheilk., Vol. XLIII, p. 531. 
27. Reuss.-Wiener med. Wochenschr., Nr. 19, 1908.

28. Richter.-Klin. Monatsbl.f. Augenheilk., Vol. LXXV, p. 475, 1925.

29. Schaeffer Parsons.-Anat. Record, 1924, ref. Zentralbl. f. Ophthal., Vol. XV, p. 78, 1925.

30. Schöninger.-Klin. Monatsbl. f. Augenheilk., Vol. LXXII, p. 526, 1925.

31. de Schweinitz. - Trans. Ophthal. Soc., U.K., Vol. XLIII, p. 12, 1923.

32. Stargardt and Schall.--Monatschr. f. Geburtsh. u. Gynäk., p. 75, 1925.

33. Wickel. - Ref. v. Hippel.

34. Zander.-Deutsch. med. Wochenschr., 1897.

\section{ANNOTATIONS}

\section{The present arrangements regarding Ophthalmic Benefits under the Insurance Acts}

Readers of this journal will probably remember that as the outcome of a conference held at the house of the Royal Society of Medicine in May, 1924, between representatives of the Council of British Ophthalmologists and of the British Medical Association, a joint committee was appointed to consider the administration of "optical benefits" under the National Insurance Act. This committee drew up a series of recommendations which are published in Vol. VIII, page 590 of this journal. These recommendations after receiving the approval of the Council of British Ophthalmologists, the British Medical Association, and the Ophthalmic Benefits Committee, were forwarded to the Ministry of Health with which prolonged negotiations ensued, the result being that the term "optical benefit" has been altered to "ophthalmic benefit." According to a communication addressed to the British Medical Association by the Ministry on October 8, 1926, the normal procedure for the administration of this "ophthalmic benefit" is now as follows :

"An insurance practitioner is required, if the condition of one of his patients is such as to require ophthalmic treatment not within the scope of his agreement with the Insurance Committee, to furnish the patient with a signed written recommendation that such treatment should be obtained. The patient then hands the recommendation to his approved society and applies for ophthalmic benefit, which request, if granted by the society, can only result in the patient being instructed to consult any one of the practitioners upon the Association's list of ophthalmic surgeons who have expressed their willingness to treat insured persons at the fee of one guinea. At the same time the society must furnish the patient with some written authority for production to the ophthalmologist at the outset of the consultation which shows that the 